\title{
Historiografía y literatura: algunas consideraciones acerca de la literatura escrita por testimonios de hechos históricos ${ }^{1}$
}

\author{
Diana Erika Cruz Jiménez \\ Licenciada en Lengua y Literatura Hispanoamericanas \\ Universidad Autónoma de Chiapas \\ https://orcid.org/0000-0001-5199-0866 \\ ErikaCrO7@outlook.com
}

\section{Resumen}

Actualmente, el análisis de la recepción de obras literarias desde el enfoque interdisciplinar permite observar otras formas de hacer historia, exponiéndola a través de narrativas que ostentan la verdad oculta y profunda del autor, de un pueblo o región; discursos basados en hechos históricos, narrados por testimonios que recurrían a la memoria y a la interpretación de sus vivencias para representarlos y otorgar otras perspectivas de análisis en las que se propone no solo galardonar a estas obras como piezas clave de la literatura, sino tomarlas en cuenta como referentes historiográficos. Para el análisis y las consideraciones que se presentan en este artículo, se retoman las ideas de Alfonso Reyes, Paul Ricoeur, Hayden White, Octavio Paz, David Mariezkurrena Iturmendi, entre otros autores que teóricamente han buscado hacer visible la intrínseca articulación entre historia y literatura de algunas narrativas, así como la apuesta interdisciplinar desde la que se deben estudiar algunas narrativas.

Palabras claves: Discurso; hecho histórico; historia y literatura; memoria; testimonio.

\section{Historiography and literature: Some considerations about literature written by testimonies of historical facts}

\section{Hbstract}

Currently the analysis of the reception of literary works from the interdisciplinary approach allows to observe other ways of making history by exposing it through narratives that hold the hidden and profound truth of the author, of a people or region; discourses based on a historical fact, narrated by testimonies that used the memory and interpretation of the facts lived to represent them and give other perspectives of analysis in which it is proposed not only to award these

\footnotetext{
1 Procedencia del artículo: Este artículo es resultados de interés académico personal.
} 
works as key pieces of literature but to take them into account as historiographic references. For the analysis and considerations that are made in this article are resumed the ideas of Alfonso Reyes, Paul Ricoeur, Hayden White, Octavio Paz, David Mariezkurrena Iturmendi, among other authors who have made analyses that seek to make visible the intrinsic articulation between history and literature of some narratives as well as the interdisciplinary commitment from which some narratives must be studied.

Keywords: Historical fact; history; literature; memory; testimony.

Recibido: 09 de abril del 2020. Aprobado: 19 de mayo del 2020

Artículo de reflexión

https://doi.org/10.25100/poligramas.v0i51.10896

\section{¿Cómo citar este artículo en MLH? - How to quote this article in MLA?}

Cruz Jiménez, Diana Erika. "Historiografía y literatura: algunas consideraciones acerca de la literatura escrita por testimonios de hechos históricos" Poligramas 51 (2020): n. pág. Web.

Fecha de acceso (día, mes en mayúscula y abreviado, y año).

\section{Introducción}

Este texto es un prolegómeno que forma parte de un trabajo más amplio; en él se reflexiona en torno a las narrativas que articulan la disciplina histórica con la literaria. Aunado a esto, se busca ampliar el panorama de análisis y recepción de obras narrativas escritas, incluso, antes de la profesionalización de la disciplina histórica en México, lo que no se da hasta 1939, cuando se crea el Instituto Nacional de Antropología e Historia. Tales obras mantienen como particularidad la constante presencia del testimonio de un hecho histórico, exponiendo en el discurso la interpretación y recreación que hacen del acontecimiento los autores.

El diálogo entre historia y literatura ha sido motivo de obras literarias y tratados teóricos en los cuales se observa el entramado de disciplinas que proponen la interdisciplinariedad, sin que una se sobreponga a otra, pues, de manera simbiótica, se articulan y resultan de estas nuevas narrativas. La literatura se vuelve el soporte de la ciencia, la historia, las matemáticas, la sociología y la psicología, no desestima a ninguna, y, al ser esta su virtud, se convierte en un 
referente social e historiográfico, exponente de los traumas sociales, denunciante de su gobierno, revelador de verdades ocultas que solo pueden enunciarse a través de la ficcionalización de la literatura.

Algunas obras literarias escritas a partir del testimonio de un hecho histórico llaman la atención por su estructura y temática, pero sobre todo por convertirse en un referente para la historiografía, ya que la perspectiva y posición social desde la cual los autores percibieron los hechos define el impacto que tuvieron en su historia de vida, y la importancia del lugar desde el cual vivió el acontecimiento y las verdades íntimas que han sido opacadas por la historia oficial, la cual tiende a generalizar el hecho sin detenerse en las particularidades de cada región, son expuestas en la narrativa de cada uno y revelan una verdad profunda. No obstante, a pesar de que en el universo literario se pueden encontrar narrativas de calidad histórica, estas tienden a ser desestimadas por críticos e historiadores, ya que la asociación de la literatura con el concepto de "mentira» como sinónimo de "ficción» es común, mas quienes lo afirman son aquellos que no han profundizado en la naturaleza de la literatura, sus géneros, su teoría y su carácter multidisciplinario.

Alfonso Reyes afirma que no hay literatura en estado de pureza (56), ni historiografía límpida; ninguna disciplina puede jactarse de solventarse por sí misma sin que otra la enriquezca. En El deslinde, Alfonso Reyes define la función ancilar como los préstamos de servicios que existen entre disciplinas del espíritu, sean de índole temática, semántica o noemática. El servicio de la función ancilar puede ser directo o inverso; en el primer caso, el préstamo es de lo literario a lo no literario; en el segundo, lo literario toma de lo no literario. Ya sea que la literatura ficcionalice temas históricos, o la disciplina histórica tome el estilo y recurra al imaginario para construir la narración, ambas disciplinas se articulan y han encontrado la comunión para poderse manifestar; incluso, la literatura constituye el espejo de verdades profundas:

La literatura puede ser citada como testigo ante el tribunal de la historia o del derecho, como testimonio del filósofo, como cuerpo de experimentación del sabio. Cuando parecen haberse agotado sus documentos más externos, todavía puede darse indicios sobre la conciencia profunda, sobre el estado mental de un hombre, sus asociaciones metafóricas, sus "constelaciones" y "complejos" (56). 
Paul Ricoeur dice que "la historia imita en su escritura los tipos de construcción de la trama recibidos de la tradición literaria" (906); la obra sería un gran libro de historia y una extraordinaria novela. Para Reyes, la "novela historiante" puede ser corroboración o fuente auténtica o relativa -de acuerdo con la dosis de historia que la obra literaria aproveche-; "lo sorprendente es que esta interconexión de la ficción con la historia no debilita el proyecto de representancia de esta última, sino que contribuye a realizarlo" (96-98). Ricoeur reconoce, al reconstruir la representación de hechos históricos, que la ficción juega un papel importante. Existen huecos que la literatura cubre sin debilitar el carácter histórico; se trata de representaciones de acontecimientos que la memoria realiza de manera inexacta. En el discurso histórico también se desmantelan intereses, fines y medios según la postura del historiador. Ricoeur señala que, por ejemplo, la descripción de la Revolución francesa realizada por Michelet es comparable a Guerra y paz de Tolstói, donde el movimiento procede de la ficción a la historia y no de la historia a la ficción. La literatura ha demostrado su compromiso y capacidad para desempeñarse en el campo de la historia. Luis Alberto Arrioja, en el seminario "Los cabildos: Nuevas perspectivas para su estudio", advirtió que los literatos en otras partes del mundo son los que están recuperando importantes acontecimientos históricos, se hallan escribiendo historiografía y transgrediendo esas fronteras que algunos han trazado entre historia y literatura.

Alfonso Reyes indica que el procedimiento literario por excelencia es la ficción. En los historiadores encontramos el recurso constante a las ficciones para representar lugares y personajes, con descripciones en las que hay reflejos imaginados y con retratos en los que parece que presta su pluma al novelista, por lo que las características narrativas se vuelven similares, aunque no persigan los mismos objetivos (71); en su caso, a la literatura no le preocupa demostrar con documentos los hechos que relata; para la historia, los documentos constituyen su base.

Paul Ricoeur recuerda que se ha pretendido separar a la literatura de la disciplina histórica; esto tiene que ver con la documentación y con lo que han dicho historiadores clásicos, como Von Ranke, y se ha mal interpretado:

A la expresión de Ranke: conocer el pasado wie es eigentlich gewesen (el pasado tal como se ha producido realmente.) El wie -que equilibra paradójicamente el eigentlichadquiere entonces el valor tropológico del "tal como", interpretado, alternativamente, como 
metáfora, como metonimia, como sinécdoque, como ironía. Lo que Hayden White llama función "representativa” de la imaginación histórica (Von Ranke en Ricoeur 907).

Este "tal como» demuestra la flexibilidad de ese "como fue», "como pudo haber sido" o "tal y como se recuerda», y, en el caso de las narraciones que parten de un hecho histórico testificado, debe tomarse como verdadero, ya que expresa la verdad de quien vivió los acontecimientos.

La historiografía y la historia literaria son narraciones, productos de un sujeto que escribe a través del tiempo, que cuenta una verdad en la que tanto lector como autor establecen un pacto: el lector creerá lo que narre el autor, mientras este último cuente con ingenio una situación. La historiografía puede ser una buena historia literaria y la historia literaria puede ser una fuente historiográfica; una mala historiografía, al igual que una desafortunada historia literaria, sería una negación en la historia, pues son narraciones que deben atrapar a su lector con su estilo narrativo. Ambas disciplinan construyen conocimiento a través del discurso; cada una se puede apoyar en las herramientas de la otra. Castro Hernández Pablo dice que una construcción narrativa no es más que una representación de las cosas a través del lenguaje, donde se edifican percepciones e ideas sobre el objeto de estudio.

La historia se vale de algunos recursos literarios para recrear la narrativa de los sucesos históricos. Hayden White menciona que el historiador es un narrador, su sensibilidad lo conduce a elaborar un relato sobre un conjunto de hechos que deben ser representados lo más fielmente posible a la «realidad» (112); se busca reconstruir de manera "objetiva» los hitos del tiempo que marcan la estructura social, filosófica, política y económica de un país y del mundo, para tratar de comprender su presente. Al no haber una realidad, sino realidades, y al ser un sujeto el que las observa, este deja huellas del acontecimiento en manuscritos, actas, objetos, pinturas o fotografías y las fuentes orales que no están desligadas de subjetividad; la ciencia no está libre de subjetividades.

La literatura también se ha servido de documentos y archivos históricos para reconstruir historias, desde las cartas, que se convierten en testimonios para escribir la biografía de un individuo, hasta las actas y documentos, que se encuentran en los archivos de la nación, y las entrevistas, que se recogen para comprender el desarrollo de ciertos momentos. 
Al igual que el historiador, que no solo recauda documentos y los reescribe de manera cronológica, sino que se vale de la imaginación para completar el ejercicio histórico y dar sentido a lo que parezca inconexo, el literato cumple con el compromiso histórico al documentarse para cargar de sentido la ficción con temas históricos.

\section{El testimonio, la recreación literaria del hecho y las verdades históricas}

Muchos escritores se han propuesto ligar su quehacer estético a la disciplina histórica, valerse de los artificios literarios y construir discursos historiográficos con cierta precisión. Este es el caso de la llamada "novela de la revolución», que, al pertenecer a la corriente literaria del realismo, incluye datos, fechas; algunos pueden tomarse como referentes o posibles fuentes historiográficas, aunque no sea su principal función servir como tal. Si bien su pretensión es literaria, puede incluir datos históricos que no están en pugna con los efectos estéticos que matizan la obra. En este sentido, la verdad histórica no está separada de la verdad poética a la que se refiere Octavio Paz en El arco y la lira (2003), donde señala que las palabras en el poema van más allá de su significado simple; en ellas existe algo más íntimo que se encuentra oculto y que el lector debe develar para no quedarse con una idea superficial o equívoca de lo que se quiso decir. Alfonso Reyes dice que la novela es susceptible de ofrecer a la historia descubrimientos o corroboraciones voluntarias, involuntarias y aun violentas (99); ahí se encuentra también la exposición histórica, intencional. Hay una historicidad latente en la novela; también el historiador inserta recursos literarios a la historicidad.

Algunos historiadores afirman que la base de sus argumentos y de la reconstrucción del pasado son únicamente los documentos, las fuentes, los archivos; no obstante, este factor no es suficiente, pues se puede corroborar el dato con la documentación y los archivos, pero la transcripción de datos es también una interpretación de los hechos de quienes escribieron esos documentos y tienen una postura ante lo investigado.

A propósito de las pruebas documentales en la narración, Paul Ricoeur dice que son condicionamientos que se les imponen a los escritores que buscan los cruces entre las narraciones históricas y literarias; estas no se limitan a los datos que encuentra, sino que exploran en las profundidades, representan una determinada época de la historia y vitalizan un 
documento rígido que pasa desapercibido a cierta clase social, personajes e historias locales. Por tanto, Ricoeur formula la pregunta: “¿Quién es más insolvente, el historiador o el novelista?" (917). Hayden White afirma que la historia no es más que una forma de ficción; todos vemos la misma historia, pero la contamos de manera distinta (45). Los hechos históricos son acontecimientos sociales en los que, a pesar de ser un solo hecho, la experiencia individual de cada uno está relacionada con la distancia temporal entre el acontecimiento y el sujeto, con su posición social y económica, su carácter y su cultura. He realizado un esquema para exponer lo siguiente:

Cuadro 1.- El hecho real

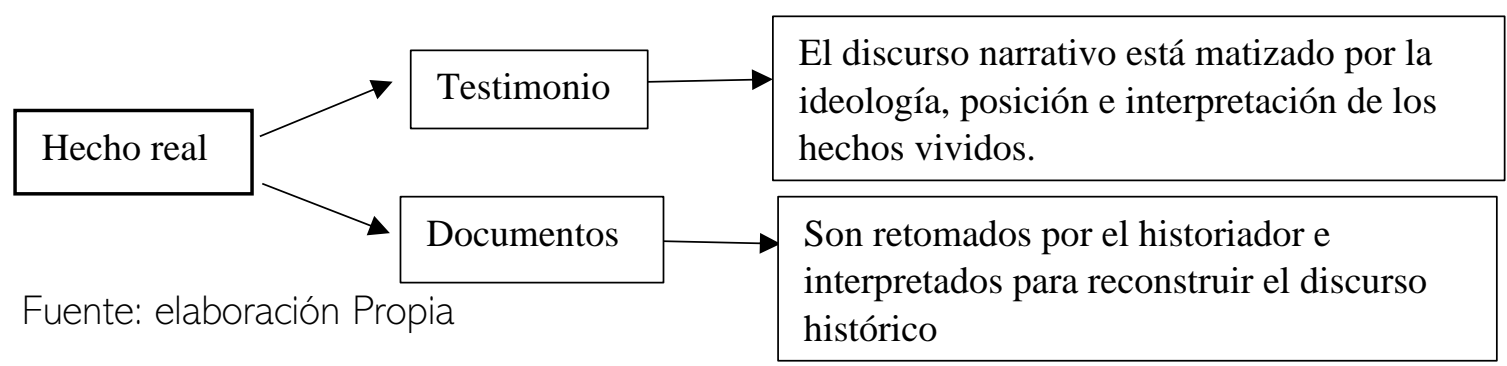

Es importante considerar a los autores que han escrito narrativas históricas a partir de su experiencia, porque constituyen testimonios vivos, ya que vivieron en carne propia los estragos de guerras y las revoluciones. A partir de esas vivencias, escribieron novelas de calidad literaria, las cuales se diferencian de aquellas narrativas de corte histórico en las que el autor se basó en una documentación para la recreación del espacio en el que desarrollará su historia.

Dichas obras literarias surgidas a partir de la memoria, que recuerdan los testimonios, se pueden abordar como discursos historiográficos, como textos referenciales dentro de un contexto histórico, que, incluso, pretenden ofrecer datos con "objetividad», con precisión, apegándose a la historia oficial, pero que, por ser expuestos desde el espacio literario, no dejan de ser efectos de realidad (es decir, artificios literarios); ejemplos de ello son: Cartucho (1931) y Apuntes sobre la vida militar de Francisco Villa (1940) de Nellie Campobello, Tropa vieja (1937) de Francisco Urquizo, Los recuerdos del porvenir (1963) de Elena Garro, e incluso Balun Canán (1957) de Rosario Castellanos. Las obras mencionadas narran acontecimientos 
históricos como la Revolución mexicana, la Guerra Cristera y el enfrentamiento en Comitán, Chiapas entre hacendados e indígenas, que son muestra de la mentalidad por diferenciarse fisiológicamente y socialmente un grupo de otro.

La memoria y la recreación juegan en estas narrativas valores fundamentales para comprender la historia oculta y profunda de los pueblos que la historia oficial, al generalizar o enfocarse en el centro del país, dejó relegada. Estos elementos, además, exponen la posición social desde la cual percibieron los acontecimientos los autores, el sector menos privilegiado al que la historia oral y la preservación de la memoria colectiva enriquecieron, y el estilo con el que escribieron sus obras. Al respecto, David Mariezkurrena Iturmendi plantea que:

Es cierto que la memoria realiza siempre un proceso de selección de los recuerdos archivados en la mente humana, debido por un lado al grado de conocimiento de un tema concreto sobre el que una persona es cuestionada, como a la implicación y el nivel de interés que se tenga con ese tema. Pero los recuerdos nos enseñan cómo diversas gentes pensaron, vieron y construyeron su mundo y cómo expresaron su entendimiento de la realidad (229).

Al tratarse de un juego entre testimonio, memoria y fuente las críticas de algunos estudiosos hacia esta forma de historiar ha sido estigmatizada; no obstante, la base histórica es precisamente la fuente testimonial de quien escribe, denotando en este el papel de juez que puede corroborar o desechar el dato que la historia oficial otorgue.

La historia escrita, a partir de la cual se presenta el testimonio de un hecho, es una representación de la interpretación de lo vivido u observado. Por su parte, la realidad histórica es lo real acontecido y es inasequible por lo efímero de las acciones. Aun siendo un hecho de larga duración, lo que se observe en el proceso y se escriba continuará siendo una interpretación de lo sucedido. A finales del siglo XX, este señalamiento fue retomado y aceptado en el gremio. Juan Carlos Ruiz (ctd. en Conrado,) ahondó en esta idea:

Con el ahora denominado retorno o resurgimiento de la narrativa y tras décadas de fuertes impugnaciones positivistas y objetivistas a las bondades de la representación literaria al servicio de la representación histórica: mientras el historiador narrativo tradicional aspiró a la mimesis de la historia vivida, las humanidades y las ciencias sociales 
en formación reconocieron en el discurso una cualidad multifacética con capacidad para soportar una gran variedad de interpretaciones de significado (4).

Es natural encontrar rasgos subjetivos en las representaciones que se hacen, a pesar del esfuerzo de que estas sean objetivas. Aunque exista el temor a la falsedad que se pueda dar en la representación, aquí podemos hablar de tres cuestiones importantes: la primera es acerca de la ética de quien hace una representación, que se refleja en el discurso y el espectador puede percibir este compromiso en la exposición; en segundo lugar, se encuentra la expresión, o la forma en la que se proyecta o narra un hecho, que no está separada del uso de algunas metáforas, hipérboles, epítetos, metonimias, entre otras figuras retóricas de las que los sujetos se valen al expresarse no solo de forma oral, sino también visual, musical y escrita, y que permean la representación; la tercera es la forma mental que toma un evento específico, el significante del significado, que es el concepto y referente universal que tenemos acerca de algo o alguien, aunque el significante varía en cada uno. Un ejemplo puede ser la Guerra Cristera (1926); de manera general, la mayoría conoce aspectos de este suceso, las razones por las que tuvo lugar y pueden hablar del tema, pero quien haya vivido este acontecimiento puede vincularlo con una experiencia concreta.

Torres Rojo (ctd. en Conrado) señala que suele recaer ambigüedad sobre lo expresado, dado que la confirmación de la verdad o la falsedad de lo expresado corresponde a la hermenéutica de la expresión. La figuridad de las proposiciones son solo significativas en su relación con la estructura de la verdad y, aunque auténticas históricamente, no lo son en su realidad primera como sentido figurado o enunciado traslaticio de predicados reales, los cuales, en su configuración absoluta, son irreductibles a las propiedades de la lógica, configurando más bien un lado especial de la inconceptualidad y, por tanto, de la verdad y su comprensión.

Lo metafórico es una de las auténticas modalidades de comprensión y, al igual que lo simbólico y lo mítico, pasan por el lenguaje y se enuncian tal y como se les interpretó, se les figuró o se les asumió; por tanto, la falsedad, que es uno de los temores más grandes de los historiadores, no debe perseguirse para juzgarse, sino que debe ser entendida como una forma mental ligada a la relación objeto-sujeto y su historicidad, linguisticidad y temporalidad. Karl Popper, en Realismo y el objetivo de la ciencia, sostiene que "la búsqueda de la verosimilitud es una meta más clara que la búsqueda de la verdad" (62). 
Al respecto, la tradición hermenéutica, cuyos principales exponentes son Martín Heidegger, Wilhelm Dilthey, Friedrich Schleiermacher y, especialmente, Hans-Georg Gadamer, plantea que todo texto debe tenerse por verdadero, en el mismo sentido en el que Octavio Paz señala que lo que va implícito en el decir del poeta encierra otras verdades, su palabra nunca es enteramente histórica. La verosimilitud es la clave de la interpretación, ya sea de quien ha vivido los hechos y los ha interpretado para escribir un discurso con pretensiones historiográficas, o de los historiadores que interpretan los documentos de los cuales se valen para escribir discursos historiográficos. Por tal razón, la disciplina histórica pretende la verdad histórica, mientras que las representaciones literarias pretenden aún más que esto, enuncian la verdad poética o la verdad profunda que la historiografía no se atreve a expresar. Ambas se basan en datos que otros interpretaron de esa forma; son vestigios de una representación que puede fundamentar lo que buscan exponer como verdadero. La única diferencia quizás entre historia y literatura son los estilos de narración de la interpretación y los tipos de discursos que construyen, pues cada uno persigue distintos propósitos de acuerdo a las intenciones.

La hermenéutica desde las disciplinas filosófica y literaria ha buscado contribuir y compartir con la historia intereses que permitan articularse y llegar a "lo real», mediante metodologías que lo acerquen a la comprensión de un hecho. La hermenéutica es la ciencia de la interpretación y la recreación de un hecho o texto redactado con un sentido histórico. El problema, en un principio, fue establecer el método con el que procedería la hermenéutica para relacionarse con una disciplina como la histórica, en la cual las fuentes y la objetividad desempeñan un papel primordial. No obstante, la hermenéutica basada en los principios de intencionalidad integra a objeto y sujeto para construir la "conciencia» de la comprensión de lo real, accediendo de esta forma al "círculo hermenéutico de la comprensión», como construcción de un sujeto temporal que supone el reconocimiento de diferentes lenguajes y accesos a la realidad.

En este sentido, Hans-Georg Gadamer en su obra Verdad y método apunta que la temporalidad juega un papel crucial para explicar que todo lo que se expresa sobre lo acontecido en el pasado se trata de una interpretación, debido a que el tiempo separa al sujeto de su objeto de estudio. Ya no se está presente para capturar lo acontecido hace años; lo observado es capturado con los ojos; la memoria puede retener, pero no es copia fiel de lo acontecido; el hecho, tal y como sucedió, pertenece al pasado y es el pasado el que lo convierte en objeto, 
toda vez que el sujeto que fue testigo del hecho histórico puede situarse a distancia de su objeto para comprenderlo y captar las intenciones racionalmente. Lo comprendido e interpretado es lo que podrá representarse, pensar según sus conceptos e imágenes y "no según las nuestras, y avanzar por ese camino hacia la objetividad histórica, éste era el presupuesto ingenuo del historicismo" (19), apunta Gadamer en Vom Zirkel des Verstehens. Por esta razón, en el último siglo se ha llegado a articular la hermenéutica con la historia; los teóricos más flexibles y sensibles tuvieron la necesidad de reconocer los vínculos sólidos entre ambas disciplinas.

La hermenéutica no castiga la libertad creadora, esa posibilidad de enunciar tal y como se comprendió, partiendo del significante del sujeto que le permite restablecer lo vivido, lo narrado u observado, rememorar el pasado tratando en todo momento de no dejar escapar algún aspecto menospreciado o desapercibido por los historiadores positivistas. La ficción no está desprovista de historicidad o, dicho de otro modo, realidad, pues retoma de esta experiencia la base para acceder a otras realidades y posibilidades.

Pretender la verdad universal es una idea ingenua. Si la historia busca representar la verdad, ¿la literatura, entonces, representa lo aparente? La verdad histórica no es unívoca e inapelable, dado que es un entramado de subjetividades. La verdad es inasible, hay interpretaciones verdaderas para diferentes sujetos; por ello es que encontramos ensayos como "Historia de un error», "Historicidad y deconstrucción», "Historia y narración», en Historia de la hermenéutica de Maurizio Ferraris, que rompen con los presupuestos históricos ligados a la validez, comprobación y desestimación que se aplican a la literatura basada en representaciones históricas.

De ahí que estudiosos como Francoise Moulin Civil, con el texto «Historia y ficción en El mar de las lentejas (1979) de Antonio Benítez Rojo»; Wolfgang Iser, con «Ficcionalización: la dimensión antropológica de las ficciones literarias», y Martina Guzmán Pinedo, con «Algunas consideraciones sobre la ficcionalización del discurso histórico», hayan abordado este tipo de textos. Uno desde la disciplina literaria y los dos últimos desde la histórica conciben este concepto, que media entre la historia y la ficción, como un entramado de tejidos complementarios y de signos mutuos que propugnan la misma ambición: la de reordenar, reconstruir la realidad e incorporar a sus respectivas disciplinas el imaginario, esfuminando fronteras que separan la invención literaria y la reconstrucción histórica. 
Investigadores españoles han manifestado, de igual forma, su interés en este tipo de textos, que muestran en su discurso híbrido intenciones históricas expuestas con un estilo literario que es el que mejor accede a expresar las verdades íntimas de los autores y permite observar otra forma de hacer historia, en la cual el medio para ser referida es la literatura, debido a la vena artística de los escritores. Recientemente, la revista española Letral, en su artículo «Presentación. Autoficción, discurso político y memoria histórica», abordó, en específico, este tipo de discursos en los que, desde la literatura y el cine, artistas que fueron testigos de hechos históricos dieron a conocer revelaciones acerca de estos acontecimientos que marcaron su vida y el estilo de su obra, la cual se volvió una forma de historiar que da a conocer la perspectiva desde la cual vivieron los acontecimientos y la manera en la que esto marcó a un pueblo y a sus familias, así como la proporción de informaciones que contribuyeron a complementar los datos proporcionados por la historiografía. Se destacan de la revista las participaciones de Julio Prieto, con «Autoficción y memoria colectiva»; Patricia López-Gay, con "Lo visto y no visto en la autoficción testimonial», y Patricia Partnoy, con "La escuelita»; estos autores forman parte del grupo de investigación del proyecto del Plan Nacional "Pensar lo real: autoficción y discurso crítico» cuya propuesta es precisamente analizar estos discursos que articulan lo histórico, lo literario y el cine, a través de la memoria del testimonio.

En el caso mexicano, poco se han rescatado, desde la disciplina histórica, a estos discursos, que, por el contrario, han sido bien acogidos y reconocidos en la literatura. Sin embargo, estos no han llegado a considerarse como un aporte historiográfico, debido a que la recepción de sus obras, a través del tiempo, continúa perpetuándose como una tradición literaria, sin que los estudiosos se ocupen de analizar más allá de la endogamia de una disciplina que se les presenta cómoda. En «Entre historiografía y literatura» de Monika Wehrheim, que se encuentra en Actas del XV Congreso de la Asociación Internacional de Hispanistas I, del 2007. se analiza la Historia general de las cosas de Nueva España de Bernardino de Sahagún, que, en principio, fue una obra considerada por la disciplina histórica como un texto propio de la historiografía mexicana y clave para el estudio de la época prehispánica y la recuperación de la cultura indígena; posteriormente, estudiosos alemanes percibieron la estética de su narrativa, el estilo poético de su discurso, lo cual llevó a una revalorización de la obra desde la disciplina literaria. 


\section{Conclusión}

Obras como Cartucho (1931) de Nellie Campobello y otras surgidas a partir de la Revolución mexicana (1910-1921), así como otras narrativas que parten del testimonio de la Guerra Cristera y demás acontecimientos importantes en el país, se reconfiguran, ante este análisis, al permitir valorarlas desde diferentes disciplinas y en articulación con la literatura. Es importante reconocer las narrativas que en el mundo tienen lugar a partir de la reconstrucción de hechos históricos y la perspectiva de un testimonio vivo, y que han sido únicamente valoradas en el universo literario sin aprovechar los datos, las informaciones y los elementos históricos que en ellas se encuentran esperando para ser analizados.

Las verdades toman vehículos -en ocasiones la metáfora- con el fin de expresar las verdades ocultas, aquellas inaccesibles o indecibles para la disciplina histórica, por el riesgo de emitir juicios, de lacerar apariencias. Es por ello que encontramos historia hecha literatura, que encuentra en la disciplina la mejor forma de expresar libremente esas realidades. Obras literarias de este corte aprovechan el argumento histórico para desplegarlo en el lenguaje literario y se convierten en nuevos paradigmas.

La invitación es hacer, según estas consideraciones, análisis de obras que, desde perspectivas que permitan reconocerlas como interdisciplinarias, hagan visible el esfuerzo de cada autor por registrar su testimonio y datos que la historiografía pueda desconocer, debido al hecho de que la generalización de una tendencia por observar la historia de centro hacia afuera impide observar estas regiones, en las que los hechos se vivieron de una forma distinta. 


\section{Referencias}

Arrioja, Luis. Seminario "Los cabildos: Nuevas perspectivas para su estudio",llevado a cabo en las Instalaciones de la Universidad de Ciencias y Artes de Chiapas, 2019.

Castro Hernández, Pablo. "Representación y memoria histórica: una revisión a los problemas de la realidad histórica y literaria, la verdad y la ficción y la construcción del conocimiento cultural". Cuadernos de historia y cultura. Dic. 2015: 119-143. Digital.

Gadamer, Hans- Georg. Verdad y método. Salamanca: Ediciones Sígueme, 1999. Impreso.

"Vom Zirkel des Verstehens" 70 (1959), en Historia de la Hermenéutica, de Ferraris Maurizio. Argentina: Siglo XXI, 2005.

Iturmendi Mariezkurrena, David. "La historia oral como método de investigación histórica". Gerónimo de Uztariz. 23.24. 2008: 227-233. Digital.

Moulin Civil, Francois. "Historia y Ficción en El mar de las lentejas (1979) de Antonio Benítez Rojo". Centro Virtual Cervantes. <2004>. Web.

Reyes, Alfonso. El deslinde. México: El Colegio de México - Fondo de Cultura Económica, 1944.

Ricoeur, Paul. Tiempo y Narración: Configuración del tiempo en el relato de ficción y configuración del tiempo en el relato histórico (volumen / y II). México: Siglo XXI, 2013.

Paz, Octavio. La casa de la presencia: Poesía e Historia. México: Fondo de Cultura Económica, 2014.

Popper, Karl. Realismo y el objetivo de la ciencia. Madrid: Tecnos, 1985.

Wehrheim, Monika. "Entre historiografía y literatura". Actas del XV congreso de la Asociación Internacional de Hispanistas /. México: Fondo de Cultura Económica, 2007.

White, Hayden. El texto histórico como artefacto literario y otros escritos. Barcelona: Ediciones Paidós, 2003. 